\title{
NÃO RECUSAR O QUE É DE DIREITO
}

\author{
Renata Guarido
}

\section{EM AGRADECIMENTO}

O convite para escrever este artigo me trouxe a grata possibilidade de fazer um agradecimento público, que não faria de outra forma. Considero os anos vividos em parceria com professoras e supervisoras, agora colegas, que integram ou integraram o Serviço de Psicologia Escolar da USP, anos de formação. No Serviço, pude, pela primeira vez, habitar um universo que me encantava desde antes: a infância, suas instituições, a educação.

Digo que naqueles encontros houve formação, pois havia transmissão de uma posição a partir da qual pensávamos o trabalho. Uma posição atenta a encontrar os sujeitos no território do trabalho das escolas; a como as produções destes sujeitos são qualificadas discursivamente, de que maneira atos e silêncios circundam os alunos, suas famílias, sua condição social, econômica, étnica e sexual. Nossa atenção dirigia-se aos sujeitos, para além dos indivíduos, sujeitos às instituições escolares com as quais trabalhávamos, das quais nos aproximávamos.

Eu poderia dizer, hoje, que o trabalho junto ao Serviço de Psicologia Escolar me transmitiu uma articulação entre sujeito e discurso que tentarei desenvolver ao longo deste artigo.

Assim, espero poder escrever um texto em agradecimento às docentes e profissionais ligadas diretamente ao trabalho do Serviço de Psicologia Escolar da USP, já que, ali se fez uma escola para mim.

Na história da proximidade entre a Psicologia e a Educação, sabemos que a primeira cumpriu papel muito mais alienante do que libertador. Os escritos de Maria Helena Souza Patto nos fizeram ver isso sem álibi. Certas práticas em Psicologia dedicadas à escola funcionaram mais como operações classificatórias, quantificadoras e adaptativas - quando sustentaram "cientificamente" o binômio normal/anormal - do que contribuíram para o questionamento de práticas disciplinares e excludentes. Exemplo destas propostas foram os laboratórios de psicometria "do escolar" que perduraram tanto tempo nas escolas e direções regionais da educação e que ainda ressurgem na forma de "projetos de acompanhamentos individuais" na esperança de avaliar, tratar e adaptar alunos em "desajuste".

Entre as décadas de 1970 e 1980, surgiram, nos campos da Saúde Mental e da Psicologia Escolar, críticas que se aproximaram na discussão acerca do caráter estigmatizante, adaptativo e disciplinar de tratamentos, bem como de avaliações e proposições psicológicas feitas sobre os alunos. Exemplo disso foram o Movimento Antipsiquiátrico, as discussões da Psicoterapia Institucional, bem como os trabalhos que apontaram a Psicologia e a Escola como instituições participantes da produção do fracasso escolar, representados pelo trabalho inaugural de Maria Helena Souza Patto (20 I 5) em "A produção do fracasso escolar". 
Ao comemorar os quarenta anos de existência do Serviço de Psicologia Escolar da USP, comemoramos a possibilidade de uma prática que infletiu a direção comumente dada à Psicologia na escola, uma prática nova, que se dedicou a questionar os acontecimentos dentro da escola, analisando sua extensão por outra perspectiva que a de um suposto valor científico da Norma, da medida, da correção daquilo que "destoasse" nos percursos de relações e aprendizado dos mais diversos sujeitos nela incluídos. Comemoramos também uma prática engajada na denúncia do preconceito de classe, racial, de gênero, entre outras presenças que pudessem ser desqualificadas e/ou equacionadas numa causalidade ideologicamente marcada. Trata-se, desde então, de um enraizamento político das práticas em Psicologia dentro da escola.

\title{
BREVE (DES)ARTICULAÇÃO ENTRE CAMPOS ${ }^{1}$
}

\author{
A desordem não se administra. É a partir dela \\ que se torna possível uma dialética. \\ Maud Mannoni
}

O encontro entre Saúde e Educação, em uma perspectiva que ganhou força desde as primeiras décadas do século $X X$, se alicerça sobre o que nomeamos como medicalização dos sofrimentos psíquicos e dos problemas de aprendizado vividos pelas crianças e jovens em suas trajetórias escolares.

Seja em sua faceta higienista, seja em sua vertente psiquiatrizada, a medicalização, seguida de perto também pela psicologização do discurso escolar, acabou por individualizar os problemas enfrentados pelos alunos, não incluindo a escola como dispositivo fundamental na produção dessas problemáticas - o que teve por efeito também deixar a escola com poucos recursos internos para fazer frente aos problemas enfrentados em sua tarefa de ensinar.

A articulação entre Saúde e Educação tem nos ocupado, ou nos preocupado, pois tem resultado em condições mais adversas do que propícias para os alunos realizarem seus percursos escolares e sociais. Mas, há uma dissimetria importante entre esses campos. Em Saúde Mental e Educação, Voltolini aponta diferenças entre eles, que nos servirão de referência: "digamos de saída para distinguir as duas lógicas com clareza: a lógica médica é de máxima objetivação enquanto a lógica educativa é de máxima subjetivação" [grifos do autor] (Voltolini, 20 I6, p.88).

Na Saúde, tem figurado uma hegemonia do modelo médico científico na apreensão dos fenômenos humanos. A medicina, nas vertentes psiquiátrica ou neurológica, vem exercendo um olhar sobre os alunos que apresentam problemas em seus percursos escolares, e a partir de suas observações tem respondido com classificações pautadas

I Trabalhei mais longamente sobre esta articulação em minha dissertação de mestrado. Remeto o leitor a ela: Guarido (2008). 
nas determinações dos manuais diagnósticos, que se orientam pela máxima objetividade possível (ou suposta). Assim, não raro, as entrevistas médicas estão baseadas em determinados sinais, de um conjunto maior, que, quando reunidos, autorizam a enunciação de uma conclusão diagnóstica. Respondendo à máxima objetividade, a prática diagnóstica deveria garantir também a suposta isenção cientifica do observador e a consequente validade da classificação proposta (ou encontrada).

De outro lado, a Educação se sustenta na "máxima subjetividade", como sublinha Voltolini (2016), já que está pautada pela relação professor-aluno, jamais objetivável a partir de certos sinais, porque é tributária do contexto de cada época e da história particular de cada um dos envolvidos.

Dessa perspectiva, "o professor terá que considerar em seu ato as várias dimensões presentes na determinação do comportamento de seus alunos, em vários planos, numa visão complexificadora, uma vez que seu objetivo é o de produzir mudanças subjetivas no aluno, enquanto o médico visa produzir mudanças objetivas no organismo" (Voltolini, 2016, p.89).

O autor nos ajuda a pensar que a lógica que sustenta o ato médico nos diagnósticos, hegemônica no campo da Saúde, e a que sustenta o ato educativo, dando possibilidade de aprendizado aos alunos, em nada se assemelham ou complementam. A articulação entre os dois campos é, no mínimo, problemática quando se pretende que um dê subsídios ou respostas ao outro, o que é pretendido quando a escola busca a explicação do fracasso de seus alunos no diagnóstico, ou quando o médico pede ao professor que relate de forma objetiva os acontecimentos escolares, visando um diagnóstico.

Com a sobreposição desses campos, o que poderia orientar um pensamento no interior da escola, na busca do esclarecimento acerca dos fenômenos da aprendizagem, fica alijado se a lógica médica (que privilegia sinais objetivos) imperar. $\bigcirc$ aprendizado e as relações entre professores e a alunos não são apreensíveis somente pela via da objetivação.

Diante das demandas de médicos e outros profissionais da saúde por relatórios que possam subsidiar seus diagnósticos, os professores figuram como informantes situados no interior de uma lógica que não lhes é própria.

Um dos desafios das práticas em Saúde e Educação reside em deslocar a lógica médica como esclarecedora dos problemas vividos no interior da escola quando se trata de ensinar e fazer aprender.

A isso, apontava Mannoni (1988, p. I 5) em Educação Impossível:

Nada poderá ser empreendido no domínio da psiquiatria e do ensino se não se começar por uma contestação radical do monopólio médico, pedagógico e administrativo [...] fonte de todos os abusos de poder. O monopólio está a serviço da hierarquia, o que não quer dizer da coletividade.

Quando nos detemos a escutar as escolas, atentamos ao discurso escolar acerca do aprendizado dos alunos, ou melhor, do seu fracasso em aprender, encontramos hipóteses que sublinham especialmente a condição do indivíduo e sua história familiar. 
Nas relações dentro da escola é vigente a crença de que aqueles que não aprendem podem ser reconhecidos pelo uso das técnicas médico-psicológicas e que, ao serem diagnosticados, terão seus problemas elucidados. Decorre ainda a expectativa de que o diagnóstico dado comporte um saber sobre o que fazer para que esses alunos possam aprender.

De acordo com Voltolini (2016, p.89):

Não se trata de contestar o peso e o valor que esses elementos levantados nas hipóteses podem ter na determinação do problema, mas, antes, de avaliar melhor em qual posição eles são colocados na elaboração das hipóteses. Normalmente são colocados como causas diretas do problema, inscritas na individualidade do aluno e expressas como tal no espaço escolar. Seja porque o aluno não tomou a medicação, seja porque houve problemas biológicos presentes na história de sua vida, ou mesmo ainda porque existiram problemas psicológicos que o marcaram ou o marcam no presente, será sempre em uma suposta interioridade do aluno que isso se achará inscrito.

Muito embora não haja uma explicação final, no campo pedagógico, que defina porque um aluno aprende, haveria, ainda assim, em um campo exterior ao escolar, a resposta ao porquê um aluno não aprende.

\section{SOBRE ARTICULAR SUJEITO E DISCURSO}

Dizer que a subjetividade humana seja efeito de linguagem é uma afirmação de Lacan ao ler Freud e pretender reorientar certas práticas e articulações teóricas na psicanálise que propôs desde o princípio de seu trabalho. Tomando a determinação inconsciente para o sofrimento humano, proposta por Freud, e as hipóteses, também freudianas, do funcionamento inconsciente, Lacan afirma que o inconsciente é estruturado como linguagem, articulando psicanálise e sua leitura da linguística. Não se trata de retomar fórmulas e repeti-las às cegas, mas de sublinhar, na escolha de uma referência teórica, alguns elementos que podem servir de base e, depois, de analisadores do tema que nos concerne.

A partir dessa perspectiva, os fenômenos subjetivos estão enraizados nos encadeamentos significantes que antecedem e circundam um sujeito, e estes, sendo matéria simbólica, respondem também ao contexto sócio-histórico de cada tempo.

Tomemos as relações entre linguagem, discurso e laço social. Os laços sociais têm seu fundamento na linguagem, campo simbólico por excelência, mas a partir desse ponto são laços discursivos, ou seja, materializam-se nos modos de relação em um dado tempo e lugar, pautando a construção da história de cada um, inserida no campo discursivo de seu tempo. Na perspectiva psicanalítica, os laços sociais remetem à condição constitutiva do homem e da civilização, 
condição esta que inaugura a entrada do homem na linguagem e na cultura (Rosa, 2017, p.23).

O enraizamento da subjetividade na linguagem, bem como a relação entre laço social e discurso podem ser lidos, entre outros textos, em $\bigcirc$ avesso da psicanálise, seminário de Lacan proferido entre 1969- 1970. Tratando de apresentar uma leitura sobre o laço social e os efeitos da articulação entre sujeito, saber e verdade (Alemán, 2002), Lacan trabalha sobre o que chama os quatro discursos ( do mestre, universitário, histérico e analítico). De forma resumida, Lacan discute os efeitos para o sujeito de que um saber se universalize, se totalize, se questione ou se analitize (Homem, 2017) e a presença do sujeito nas diversas modalidades do laço social, demonstrando as distintas maneiras nas quais encontra a afirmação ou apagamento do sujeito em cada modalidade discursiva.

Tomando estas referências na produção de Lacan - sua afirmativa de que o sujeito é efeito de linguagem e que o laço social é efeito de discurso - concluímos que, das diversas modalidades assumidas pelo laço entre os seres (resultantes históricas, culturais e das diversas produções de saber), resulta, ou não, que um ser venha a ter lugar, voz e presença, determinado por sua posição no discurso, sem, contudo, que este mesmo sujeito esteja todo ele representado por uma categoria discursiva.

Para Lacan, nenhuma significação pode abarcar a totalidade do sujeito, não havendo uma verdade última ou absoluta que representaria o sujeito em sua condição desejante. Há algo que resiste ao sentido e aos dispositivos históricos de significação. Somente certas torções poderiam fazer operar uma significação última que se supusesse "dar conta" do sujeito - tomado aqui na qualidade de uma singularidade - já que sua condição não pode ser toda vasculhada por uma única atribuição de sentido ao conjunto de suas experiências.

Como alerta Alemán (2002, p.42), "nunca se poderá negar o modo como os dispositivos históricos tentam, através do discurso do Mestre, controlar e produzir as representações do sexo, da morte, [...] codificar seus trajetos nas distintas épocas, estabelecer seus sentidos [...]".

Já Voltolini (200 I, p. 103) aponta:

[...] [o] discurso do mestre, visa "consertar" o que surge como problemático por meio de medidas práticas que interfiram naquilo que é concebido como a causa do problema. Para tanto, mas só neste ponto é que ele se interessa pelo saber, uma vez que este pode concorrer na solução do problema: um saber, portanto, amputado de sua possibilidade de investigação; um saber já sabido, "todo" do qual se retirará uma eficácia.

Tentar encontrar respostas para o mal-estar ou para aquilo que "emperra" em uma instituição, responde à tentativa de formular soluções para o que não anda bem, para o que se concebe como fracasso ou como desvio. E esta tem sido a direção de certa produção do discurso médico, situado por diversos autores como um discurso do Mestre, por exemplo, Clavreul (1983) e Gori y Del Volgo (2005). 
Visar à eficácia da instituição escolar por meio de índices de aprendizados ou fazer com que as coisas andem bem na escola não é o mesmo que dar condições de realização do ato educativo.

Encerrar o acontecimento do aprendizado (ou do não aprender) em explicações fixas, articuladas à lógica do discurso médico, reduz, os sujeitos em jogo ao que se profere nos diagnósticos ou laudos psicológicos. Constrange os sujeitos a uma representação última, que só aparentemente "resolve" o problema, já que todo professor encontra o limite dos diagnósticos em serem reorientadores das práticas de ensino. Os relatórios ou laudos diagnósticos vão parar na gaveta, pois nada dizem sobre os sujeitos em questão, nada revelam sobre os alunos com quem e para quem os laços na escola se sustentam; apenas os classificam.

Em sua proposição sobre o saber cientifico, Lacan sugere que "a ciência sutura o sujeito, isto é, despreza o sujeito, excluindo-o de seu campo" (Fink, 1998, p. I7I).

Nas diversas modalidades de laço social estabelecidas na escola, alunos podem dirigir-se aos professores para elucidar questões, porque não entenderam algo, porque desejam saber. Também pode ser que para derrubá-los de uma posição de Ideal (como adultos ou autoridade). Ou ainda podem responder à instituição escolar com agressão ou violência, muitas vezes em resposta ao que lhes foi imposto. Com isso quero dizer que os alunos respondem em ato àquilo que figura no discurso escolar e social sobre seu lugar: de aluno, criança, adolescente. E, ainda bem, frequentemente não se conformam a estes.

$\bigcirc$ que se espera dos alunos, quando se restringe a ter que dar mostras de seu aprendizado, oblitera manifestações singulares de cada sujeito em sua necessária produção de separação, desidealização ou defesa em relação a violências simbólicas ocorridas nos laços dentro da escola. Cada aluno/sujeito produz uma resposta a partir da qual "trata" o que lhe demandam, como o qualificam, os significados que a ele são atribuídos. É isso o que poderia qualificar uma posição subjetiva e é nesta medida que parte dos atos de um sujeito pode ser tomada como resposta, como uma elaboração psíquica daquilo que the seja endereçado.

Ao ser um lugar de pares, de semelhantes, a escola é lugar de pertencimento, e os alunos pedem reconhecimento de sua passagem por ela. Saber que ali há sua marca e sua presença, muitas vezes se faz por vias conflitivas.

O lugar de aluno é um dos pólos da relação, não complementar, que sustenta a educação no âmbito da instituição escolar: professor-aluno. Se o aluno só se positiva quando aprende, e se desqualifica quando não responde ao esperado, será que vemos desfazer-se a "liga" professor-aluno, ficando o professor diante de certo fracasso, pois no lugar do aluno impõem-se um vazio [se não aprende deixa de ser aluno] e o aluno obliterado daquilo que positiva sua presença na escola, elemento fundamental para que subjetive sua experiência escolar de ser aluno?

Revisitando Mannoni em "Educação Impossível”, Patto (20 I 5), no posfácio à quarta edição de "A produção do fracasso escolar" nos diz: 
[... ] "no desejo de tratar o sintoma, recusa-se o paciente": com o objetivo de obriga-los a aprender, os professores recusam os alunos. Em ambos os casos, orientados por técnicas tidas como verdadeiras e inquestionáveis, porque supostamente científicas, médicos e educadores, longe de procurar entendera criança como sujeito dotado de desejos próprios, integram-na como objeto de cuidados nos diversos sistemas de recuperação, privando-a de toda forma pessoal de expressão verbal, de todo direito à palavra (p.442, grifo da autora).

E segue:

A esse respeito, seria possível dizer mais: a sucessão de técnicas salvadoras impostas aos professores não produz o resultado anunciado porque os atropela, os reduz a operários de uma linha de montagem cujo produto será avaliado por critérios quantitativos que resultarão em números que justificarão a adoção de novas técnicas impostas às escolas [...]. Nesse cenário os professores não conseguem construir um "saber fazer" que tenha sua marca pessoal e, muito menos, participar da construção de um "fazer saber" que resulte da discussão coletiva das mudanças que lhes foram impostas com os colegas e com técnicos das secretarias. Não só os alunos são tratados como coisas, os professores também (Patto, 20 I 5, p.442).

\section{A ESCOLA É PARA ALUNOS}

Ir à escola é um direito das crianças e adolescentes, adquirido, validado socialmente, e que deve ser sustentado por todos. Mas não basta que haja um direito, e que existam escolas que o cumpram, para tornar válidas e interessantes as experiências que nela ocorrem. A estatística das matrículas nos mostra isso. A presença de $99 \%$ das crianças matriculadas no ensino básico não garante a ocorrência de um ensino de boa qualidade e com aprendizados que dele decorrem. Vide os índices de evasão, analfabetismo funcional e repetência que continuamos a cumprir.

A passagem pela escola pode ser afirmada como uma experiência fundamental. A escola é uma instituição importante naquilo que diz respeito à qualidade da infância e adolescência vividas pelos sujeitos. Sendo uma experiência que se vive coletivamente, a escola é ainda uma instituição que sobrevive dos encontros, no social, não está sustentada em relações duais e é, por esta qualidade, uma experiência civilizatória, especialmente na atualidade, quando muitos laços parecem estilhaçar.

Funcionando como um lugar de estigmatização das diferenças ou um lugar de invenção de novas trajetórias para os alunos, incluindo vida onde só havia patologia ou discriminação e preconceito, a escola é uma instituição significativa na vida de uma criança ou jovem. Passar por ela ou ficar fora dela é uma experiência que não é sem efeitos. 
Ser aluno é um lugar que não deveria ser recusado a cada criança ou jovem que pertence ao cotidiano escolar. Desta forma, o aprender seria um resultado possível de uma tarefa empreendida na escola por aqueles que, envolvidos nos processos de ensino, façam acontecer algo da ordem da transmissão de conteúdos formais e de uma posição ética diante dos outros.

A escola, por ser uma instituição social destinada às crianças e aos jovens, pode se caracterizar como lugar de pertencimento e de aprendizagem e cunha naqueles que dela participam um traço subjetivo felizmente incontornável. Entretanto, na história de nosso país, constatamos que, para alguns, este traço pode tornar-se infelizmente incontornável.

Uma escola deve fazer alunos. E isso não se faz sem uma experiência no laço social. A experiência no laço pode ser, para um sujeito, fazer sua diferença nesse encontro em que há outros nada familiares. Um aluno está marcado pela possibilidade de estar nos laços sociais munido de sua história e do conhecimento que até então adquiriu. A escola é, para as crianças, o lugar fundamental deste acontecimento, o que se vê na importância e nos efeitos surpreendentes da inclusão de alunos com suas deficiências, seus sofrimentos, suas idiossincrasias, quando estes circulam nas escolas, andam nos ônibus de uniforme confundindo-se com outras crianças que também estão ali, sumindo no grupo de crianças na hora da saída. Crianças e jovens para quem uma marca particular de sua "deficiência" pode, por um instante, apagar-se na multidão, ressurgindo como diferença, já que aquele que ali está aparece como alguém entre vários.

A entrada de uma criança na escola, ao incluí-la na experiência de ser aluno, de estar no espaço social que a escola representa, confere a ela uma posição muito diferente daquela que implica ser filho ou irmão, ou seja, um participante da vida familiar, particular, fazendo barreira a que o familiar the seja sua única referência. Assim, cada criança, desde o princípio de sua escolarização, empreende uma experiência de inclusão em encontros marcados pelo laço social, alheios ao universo familiar, estabelecidos na relação entre semelhantes, o que guarda a particular qualidade de poderem ser tanto fraternos, quanto hostis.

Situar a lógica médica em um lugar privilegiado na leitura daquilo que ocorre a um aluno quando deixa de aprender ou agride o laço social (queixas mais comuns na escola) desloca a criança ou jovem da condição de aprendiz para o lugar de paciente a ser tratado, de quem deveriam ser subtraídos os sintomas de um mau funcionamento.

É possível sustentar que recobrar uma função dirigida ao ensino e ao encontro entre sujeitos, reafirmando e reinscrevendo (não sem um posicionamento crítico acerca de certas tradições) os lugares do professor e do aluno, valeria por recolocar em operação a relação professor-aluno, impossível de ser objetivada, produzindo um laço que pode causar transformações em ambos participantes, desde que a um deles não se impusesse uma nomeação médico-psicológica.

Resulta que poderíamos ver funcionar outra medida de participação da Educação na promoção da saúde, não como denunciadora dos fracassos, informante nos relatórios, representante da higiene moral das condutas, mas como promotora de laços que restaurem a condição de alunos às crianças e jovens, sustentando sua presença como sujeitos 
de direitos e de singularidades na instituição que, por princípio ético, representa no social, ainda (?), a aposta num saber possível.

\section{REFERÊNCIAS BIBLIOGRÁFICAS}

Alemán, J. (2002). Lacan, Foucault: el debate sobre el construccionismo. Colofon. Boletin de la Federacion Internacional de Bibliotecas del Campo Freudiano, 22, 40-44.

Clavreul, J. (1983). A ordem médica: poder e impotência do discurso médico. São Paulo: Brasiliense.

Fink, B. (1998). O sujeito lacaniano. Rio de Janeiro: Jorge Zahar.

Guarido, R. L. (2008). "O que não tem remédio, remediado está": Medicalização da vida e algumas implicações da presença do saber médico na educação. Dissertação (Mestrado). Faculdade de Educação da Universidade de São Paulo, São Paulo, SP. Brasil.

Gori, r., \& Del Volgo, M-J. (2005). La Santé totalitaire: essai sur la médicalisation de l'existence. Paris: Denoël.

Homem, M. L. (2017). Lacan urgente: o analítico em tempos e estreitamento. Cult - Revista Brasileira de Cultura, 20(8), 10 - 13. São Paulo: Editora Bregantini. .

Lacan, J. ( 1992). O seminário, Livro XVII, O avesso da psicanálise. Rio de Janeiro, RJ: Jorge Zahar.

Mannoni, M. (1988). Educação Impossível. Rio de Janeiro: Francisco Alves.

Patto, M. H. S. (20 I5). A produção do fracasso escolar. Histórias de submissão e rebeldia (4a ed. rev. amp,) São Paulo: Intermeios.

Rosa, M. D. (2017). A psicanálise lacaniana e a dimensão sociopolítica do sofrimento. Cult Revista Brasileira de Cultura, 20(8), 22-24. São Paulo: Editora Bregantini.

Voltolini, R. (20 I6). Saúde mental e escola. Caderno de debates do NAAPA: questões do cotidiano escolar. São Paulo: SME/COPED.

- (200 I). Do contrato pedagógico ao ato analítico: contribuições à discussão da questão do mal-estar na educação. Estilos da Clínica, São Paulo, 6(10), 101-1 II. Recuperado em 30 janeiro, 2016, de <http://pepsic.bvsalud.org/scielo. php?script=sci_arttext\&pid=S | 4 | 5-7 | 282001000 | 00009\&lng=pt\&nrm=iso > . 
